4

\title{
Oncolytic adenovirus Delta-24-RGD induces a widespread glioma proteotype
}

remodeling during autophagy

Andrea González-Morales ${ }^{1,2,3}$, Aintzane Zabaleta ${ }^{2,4}$, Marc García-Moure,5,6, Marta M. Alonso $^{2,5,6}$, Joaquín Fernández-Irigoyen ${ }^{1,2,3} \S$, Enrique Santamaría ${ }^{1,2,3} \S$

${ }^{1}$ Clinical Neuroproteomics Group, Navarrabiomed, Complejo Hospitalario de Navarra (CHN), Universidad Pública de Navarra (UPNA), Irunlarrea 3. 31008 Pamplona, Spain; ${ }^{2}$ IDISNA, Navarra Institute for Health Research, Pamplona, Spain; ${ }^{3}$ Proteored-ISCIII, Proteomics Unit, Navarrabiomed, Complejo Hospitalario de Navarra (CHN), Universidad Pública de Navarra (UPNA), Irunlarrea 3. 31008 Pamplona, Spain; 4 Oncohematology Area, University Hospital of Navarra, Center for Applied Medical Research, CIBERONC, Pamplona, Spain. ${ }^{5}$ Program in Solid Tumors and Biomarkers, Foundation for the Applied Medical Research, Pamplona, Spain; ${ }^{6}$ Department of Pediatrics, University Hospital of Navarra, Pamplona, Spain.

$\S$ These authors share senior authorship

Corresponding author: Enrique Santamaría, PhD. Proteomics Unit, Navarrabiomed, Navarra Institute for Health Research (IDISNA), Irunlarrea Street, 3 Pamplona, CP 31008 (Spain). Phone number: +(34) 8484257 40E-mail: esantamma@navarra.es.

(C) 2018. This manuscript version is made available under the CC-BY-NC-ND 4.0 license http://creativecommons.org/licenses/by-nc-nd/4.0/

\section{Abbreviations}


32 c-Src: proto-oncogene tyrosine-protein kinase $\mathrm{Src}$

33 ERK1/2: extracellular signal-regulated kinase 1/2

34 GBM: glioblastoma

35 GSK-3: glycogen synthase kinase-3

36 MOI: Multiplicity of infection

37 MSK1/2: Mitogen- and Stress-activated protein Kinases 1 and 2

38 mpi: minutes post infection

39 hpi: hours post infection

40 p38 MAPK: p38 mitogen-activated protein kinase

41 PKA: Protein kinase A

42 PKC: Protein kinase $\mathrm{C}$

43 PP1: serine/threonine-protein phosphatase 1

$44 \quad$ PP2A: serine/threonine-protein phosphatase 2A

45

46

47

48

49

50

51

52

53

54

55

56

57

58

59

60

61

62

63

64

65

66

67

68

69

70

71

72

73

74

75

\section{Abstract}


Adenovirus Delta-24-RGD has shown a remarkable efficacy in a phase I clinical trial for

77 glioblastoma. Delta-24-RGD induces autophagy in glioma cells, however, the molecular derangements associated with Delta-24-RGD infection remains poorly understood. Here, proteomics was applied to characterize the glioma metabolic disturbances soon after Delta-24-RGD internalization and late in infection. Minutes post-infection, a rapid survival reprogramming of glioma cells was evidenced by an early c-Jun activation and a time-dependent dephosphorylation of multiple survival kinases. At 48 hours postinfection (hpi), a severe intracellular proteostasis impairment was characterized, detecting differentially expressed proteins related to mRNA splicing, cytoskeletal organization, oxidative response, and inflammation. Specific kinase-regulated protein interactomes for Delta-24-RGD-modulated proteome revealed interferences with the activation dynamics of protein kinases $\mathrm{C}$ and $\mathrm{A}$ (PKC, PKA), tyrosine-protein kinase Src (c-Src), glycogen synthase kinase-3 (GSK-3) as well as serine/threonine-protein phosphatases 1 and $2 \mathrm{~A}$ (PP1, PP2A) at 48hpi, in parallel with adenoviral protein overproduction. Moreover, the late activation of the nuclear factor kappa $\mathrm{B}(\mathrm{NF}-\mathrm{\kappa B})$ correlates with the extracellular increment of specific cytokines involved in migration, and activation of different inflammatory cells. Taken together, our integrative analysis provides further insights into the effects triggered by Delta-24-RGD in the modulation of tumor suppression and immune response against glioma.

Keywords: Adenovirus, Delta-24RGD infection, proteomics, glioma, networks, signaling

\section{Introduction}


DNX-2401 (Delta-24-RGD) is an oncolytic adenovirus that replicates selectively in

102

103

104 retinoblastoma $(\mathrm{Rb})$ pathway deficient cells and infects tumor cells efficiently (1-3). In general, results from pre-clinical and clinical studies have revealed that the adenovirus Delta-24-RGD is an attractive therapeutic agent for malignant gliomas (1, 4-7), demonstrating favorable toxicity profile and remarkable clinical efficacy (8). Indeed, novel clinical trials in combination with specific immunomodulators are currently active (Clinical-Trials.gov identifiers NCT02197169, and NCT02798406).

It is well-known that the mechanism of oncolytic Delta-24-RGD-mediated tumor suppression involves adenovirus-induced activation of the autophagic machinery in glioma cells (9). We consider that understanding the proteostatic changes associated with the viral cycle of Delta-24-RGD, will provide new avenues to enhance the capability of viral release, and, as a result, to elicit a more therapeutic effect. Using quantitative extracellular and intracellular proteomics workflows, physical and functional interaction data, and biochemical approaches, we have partially characterized the missing links in the biochemical understanding of the signaling pathways impaired during the initial phase of attachment and internalization of viral particles as well as during the autophagic phase of Delta-24-RGD infection (10-13). More than 200 differential proteins were detected in Delta-24-RGD-infected glioma cells, pinpointing protein interaction networks, specific pathways, and potential novel therapeutic targets. In addition, a specific increase in specific cytokine subsets was detected by extracellular cytokine profiling of gliomainfected cells, supporting the notion that Delta-24-RGD modulates pathways related to migration, and activation of different inflammatory cells.

\section{Materials and methods}




\subsection{Materials}

127 The following reagents and materials were used: anti-GAPDH (Calbiochem), anti-PKCPan, anti-pPKC-pan (T514), anti-pAkt (Ser473), anti-Akt, anti-cJUN, anti-phospho cJUN

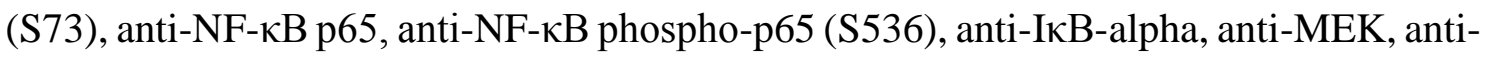
pMEK (S217/221), anti-PKAc alpha, anti-pPKAc (T197), anti-GSK-3 $\alpha / \beta$, anti-pGSK$3 \alpha / \beta$ (S21/9) (Cell Signaling), anti-PP1, anti-c-src, anti-p-c-src (Y419), anti-E1A protein

132 (Santa Cruz Biotechnology), anti-phospho PPP1A (T320), anti-PP2A $\alpha / \beta$ (Abcam), and anti-fiber protein (Neomarkers). Electrophoresis reagents were purchased from Bio-rad and trypsin from Promega.

\subsection{Virus production, culture and treatment of malignant glioma cells.}

136 The generation of Delta-24-RGD vector has been previously described $(1,3)$. U87 MG 137 glioma cells (ATCC: HTB-14) were cultured in DMEM/F12-GlutaMAX (Gibco 10565018) supplemented with $10 \%$ FBS, and $1 \%$ penicillin/streptomycin. $2.5 \times 10^{6} \mathrm{U} 87$ cells were infected with Delta-24-RGD at multiplicity of infection (MOI) of 25. After incubation for 30 minutes with DMEM/F12 $1 \%$ penicillin/streptomycin at $37{ }^{\circ} \mathrm{C}$, the

141 double of the volume of DMEM/F12-GlutaMAX (Gibco 10565018) supplemented with

$14210 \%$ FBS and 1\% penicillin and streptomycin was added to the previous media. Cells 143 were incubated under the same conditions during the indicated periods of time ( 24 and 144 48hpi).

\subsection{Mass-spectrometry based-proteomics}

146 After the indicated periods of time, the media was removed and the cells were washed 147 with $1 \mathrm{X}$ cold PBS. The cellular pellets were resuspended in lysis buffer (7M urea, 2M 148 thiourea, 50mM DTT) and let on ice for 30 minutes, spinning and vortexing each 10 149 minutes. After a sonication step, the lysate was centrifuged for 60 minutes at 20000xg at $15015^{\circ} \mathrm{C}$. Protein concentration of the supernatants was measured with the Bradford assay 
kit (Bio-rad). Total cell extracts from Mock-infected, and U87-infected cells (48hpi) were diluted in Laemmli sample buffer and loaded into a $1 \mathrm{~mm}$ thick polyacrylamide gel with a $4 \%$ stacking gel casted over a $12.5 \%$ resolving gel. The run was stopped as soon as the front entered $3 \mathrm{~mm}$ into the resolving gel so that the whole proteome became concentrated in the stacking/resolving gel interface. Bands were stained with Coomassie Brilliant Blue and excised from the gel. Protein enzymatic cleavage (15ug) was carried out with trypsin

157 (Promega; 1:20, w/w) at $37^{\circ} \mathrm{C}$ for $16 \mathrm{~h}$. Purification and concentration of peptides was performed using C18 Zip Tip Solid Phase Extraction (Millipore). Peptides mixtures were separated by reverse phase chromatography as previously described (26). The column gradient was developed in a 240 min two step gradient from $5 \%$ B to $25 \%$ B in $210 \mathrm{~min}$ and $25 \% \mathrm{~B}$ to $40 \% \mathrm{~B}$ in $30 \mathrm{~min}$. Column was equilibrated in $95 \% \mathrm{~B}$ for 9 min and $5 \% \mathrm{~B}$ for 14 min. During all processes, precolumn was in line with column and flow maintained all along the gradient at $300 \mathrm{nl} / \mathrm{min}$. Eluting peptides from the column were analyzed using a Sciex 5600 Triple-TOF system. Information data acquisition was acquired upon a survey scan performed in a mass range from $350 \mathrm{~m} / \mathrm{z}$ up to $1250 \mathrm{~m} / \mathrm{z}$ in a scan time of $250 \mathrm{~ms}$. Top 25-35 peaks were selected for fragmentation. Product ions were scanned in a mass range from $230 \mathrm{~m} / \mathrm{z}$ up to $1500 \mathrm{~m} / \mathrm{z}$ and excluded for further fragmentation during $15 \mathrm{~s}$. The MS/MS data acquisition was performed using Analyst 1.7.1 (Sciex) and spectra files were processed through Protein Pilot Software (v.5.0.1-Sciex) using Paragon ${ }^{\mathrm{TM}}$ algorithm (v.5.0.1) for database search, Progroup ${ }^{\mathrm{TM}}$ for data grouping, and searched

171 against the concatenated target-decoy UniProt proteome reference database (Human 172 database Proteome ID: UP000005640, 70902 proteins, December 2015 plus adenovirus 173 HAv5 database UP000004992, 31 proteins, September 2016). False discovery rate was 174 performed using a non-lineal fitting method and displayed results were those reporting a $1751 \%$ Global false discovery rate or better. The mass spectrometry proteomics data have 
been deposited to the ProteomeXchange Consortium

177 (http://proteomecentral.proteomexchange.org) (55) via the PRIDE partner repository 178 with the data set identifier PXD010256.

179 (For reviewers, Username: reviewer37737@ebi.ac.uk; Password: IVLEQLmD)

$180 \quad 2.4$ Data analysis

181 The peptide quantification was performed using the Progenesis LC-MS software (ver. 182 2.0.5556.29015, Nonlinear Dynamics). Using the accurate mass measurements from full survey scans in the TOF detector and the observed retention times, runs were aligned to compensate for between-run variations in our nanoLC separation system. To this end, all runs were aligned to a reference run automatically chosen by the software, and a master

186 list of features considering $\mathrm{m} / \mathrm{z}$ values and retention times was generated. The quality of these alignments was manually supervised with the help of quality scores provided by the software. The peptide identifications were exported from Protein Pilot software and imported in Progenesis LC- MS software where they were matched to the respective features. Output data files were managed for subsequent statistical analyses and representation. Proteins identified by site (identification based only on a modification), reverse proteins (identified by decoy database) and potential contaminants were filtered out. Proteins quantified with at least two unique peptides, a T-test p-value lower than 0.05 , and an absolute fold change of $<0.77$ (down-regulation) or $>1.3$ (up-regulation) in linear scale were considered significantly differentially expressed.

\subsection{Bioinformatics}

197 The proteomic data were analyzed using STRING (56) and QIAGEN's Ingenuity® 198 Pathway Analysis (IPA) (QIAGEN Redwood City, www.qiagen.com/ingenuity), to detect and infer differentially activated/deactivated pathways because of Delta-24RGD treatment. STRING database includes interactions from published literature describing 
experimentally studied interactions, as well as those from genome analysis using several well-established methods based on domain fusion, phylogenetic profiling and gene neighbourhood concepts. Accordingly, a confidence score for every protein-protein

204 association was assigned to the network. A higher score was assigned when an association is supported by several types of evidence. To minimize false positives as well as false negatives, all interactions tagged as "low-confidence" $(<0.4)$ in STRING database have been eliminated from this study. IPA software comprises curated information from databases of experimental and predictive origin, enabling discovery of highly represented functions, pathways, and interactome networks. The IPA comparison analysis considers the signalling pathway rank according to the calculated p-value and reports it hierarchically. The software generates significance values (p-values) between each biological or molecular event and the imported molecules based on the Fisher's exact test $(\mathrm{p} \leq 0.05)$

\subsection{Protein arrays}

For the secretome analysis, a dot-blot protein array was used for cytokine profiling (Abcam). Briefly, membranes with 80 cytokine antibodies were blocked with the manufacturer's blocking buffer at room temperature (RT) for $30 \mathrm{~min}$, and incubated o/n with $1 \mathrm{ml}$ of undiluted cell-cultured media from Mock- and U87-infected cells (24, 48hpi) $(n=3)$. After washing, a biotinylated anti-cytokine antibody mixture was added to the membranes followed by incubation with HRP-conjugated streptavidin and then exposed to the manufacturer's peroxidase substrate. For phospho-kinome analysis, the Proteome Profiler Array (R\&D Systems. Ref: 894552) was used according to the manufacturer instructions. Cell lysates derived from Mock- and U87-infected cells (5, 15, $30 \mathrm{mpi})(\mathrm{n}=3)$ were diluted and incubated overnight with the Human Phospho-Kinase Array, that contains 43 different capture antibodies printed in duplicate. The arrays were washed to 
remove unbound proteins followed by incubation with a cocktail of biotinylated detection antibodies. Streptavidin-HRP and chemiluminescent detection reagents were applied and a signal was produced at each capture spot corresponding to the amount of

229 phosphorylated protein bound. For both protein array platforms, chemiluminescence signals were quantified with the ImageQuant ECL system (BioRad) and normalized to the positive control signals. The Perseus software (version 1.5.6.0) was used for statistical analysis (57).

\subsection{Western-blotting}

Equal amounts of protein $(10 \mu \mathrm{g})$ were resolved in $4-15 \%$ Criterion $^{\mathrm{TM}} \mathrm{TGX}^{\mathrm{T}}$ Stain-Free ${ }^{\mathrm{TM}}$ Protein Gels (\#5678085 Bio-rad). Mock-infected and U87-infected protein cell extracts were electrophoretically transferred onto nitrocellulose membranes using Trans-Blot Turbo (BioRad) for 7 minutes at $2.5 \mathrm{~A}$ constant, up to $25 \mathrm{~V}$. Equal loading of the gels was assessed by stain free digitalization and Ponceau staining. Membranes were probed with primary antibodies at 1:1000 dilution in 5\% nonfat milk or BSA. After incubation with the appropriate horseradish peroxidase-conjugated secondary antibody (1:5000), antibody binding was detected by a Chemidoc ${ }^{\mathrm{TM} M P}$ Imaging System (Bio-Rad) after incubation with an enhanced chemiluminescence substrate (Perkin Elmer). All Band intensities were measured with Image Lab Software Version 5.2 (Bio-Rad), and normalized to GAPDH or to total stain in each gel lane (58).

\section{Results and discussion}

Glioblastoma multiforme (GBM) is the most aggressive type of malignant glioma, characterized by infiltrative growth causing progressive neurologic dysfunction (14). One of the treatment strategies currently used is the oncolytic virotherapy $(15,16)$, that combines tumoral cell lysis with systemic anti-tumor immunity induction. Delta-24RGD, also known as DNX-2401, is currently under investigation in clinical trials for 
251 GBM (8). However, the global molecular events that accompany the adenoviral infective

252 process remain to be elucidated. We consider that a system-wide characterization of

253 initial phosphoproteomic events as well as the intracellular and extracellular glioma

254 proteomes underlying the regulation of autophagy upon Delta-24-RGD infection (Figure

255 1) may provide new inducing or inhibiting strategies to improve the therapeutic effect

256 against target glioma cells.

\subsection{Delta-24-RGD-receptor interactions rapidly modulate the glioma phosphoproteome}

To identify signaling events induced soon after Delta-24-RGD engagement of cell surface (mpi). To synchronize virus binding, we added a high concentration of virus $(\mathrm{MOI}=25)$ in order to obtain a sufficient number of binding events within a very short time-frame.

262 As shown in figure 2, a time-dependent dephosphorylation of specific survival routes was observed (Akt, GSK-3, ERK1/2, p38 MAPK, MSK1/2 between others), indicating that

Delta-24-RGD induces an early survival reprogramming of glioma cells for an optimal viral replication. Akt was progressively inactivated during the time-points analysed (Figure 2A-B). Phospho-WNK-1 (T60), an Akt substrate implicated in regulating ion permeability $(17,18)$ was also dephosphorylated during the first 30 mpi (Figure 2A-B). Interestingly, the activation of $\mathrm{WNK}-1 / \mathrm{OSR} 1 / \mathrm{NKCC} 1$ signaling pathway facilitates glioma cell migration and apoptotic resistance to the chemotherapeutic drug temozolomide (TMZ) (19), reinforcing the idea that co-treatment of glioma cells with

271 TMZ and Delta-24-RGD might lead to an enhanced therapeutic effect (20). c-Jun was the 272 unique factor that rapidly increased its activator phosphorylation (Figure 2A-B). 273 Although Jun N-terminal kinases (JNKs) are the canonical regulator of c-Jun activity (21, 22), a JNK activation was not observed at 5-15 mpi (Figure 2C-D), indicating that

275 additional kinases (23) may be responsible for the c-Jun early activation peak during 
276 Delta-24-RGD attachment. Together with the shut off induced in the kinase-mediated

277 signaling, several transcription factors were rapidly inhibited (30mpi) such as STAT2 and

278 STAT5b (figure 2C-D), probably blocking the antiviral defense (24), causing cycle arrest,

279 and inhibiting glioma cell growth (25).

\subsection{Delta-24-RGD induces protein interactome derangements late in infection}

281 It is well known that for an efficient cell lysis and adenoviral spread, Delta-24-RGD

282 induces massive autophagy (10-12). We have determined the Delta-24-RGD-induced

283 glioma proteome remodelling that occurs in parallel with the overproduction viral

284 proteins and the concomitant activation of Akt and c-Jun at 48hpi (9) (Figure 3A). Among

285 the 1616 intracellular proteins consistently quantified (figure 3B and supplementary table

286 1), 240 proteins tend to be differentially expressed between Mock and glioma-infected

287 cells (127 up-regulated, and 113 down-regulated proteins) (figure 3B and Supplementary

288 table 2), being potentially distributed across nuclear, cytosolic, exosome, and membranes

289 between other organelles (Figure 3C). In addition, the over-production of 18 adenoviral

290 proteins was also detected by mass-spectrometry (supplementary table 2). In accordance

291 with previous studies $(9,26)$, Delta-24-RGD modulates proteomic fingerprints involved

292 in EIF2 and mTOR signalling (figure 3D). Changes in the expression of various autophagy-related biomarker proteins were also detected in our proteomic survey. p62 (SQSTM1) down-regulation was evidenced in Delta-24-RGD-infected glioma cells. This molecular event is a marker of autophagy in oncolytic adenovirus-infected tumor cells, where p62 may act as a receptor for ubiquitinated proteins or organelles (27), being finally

297 degraded by the autolysosome (28). The autophagosome-lysosome fusion requires the lysosomal membrane protein LAMP-2 (27), an over-expressed protein in Delta-24-RGDinfected cells. Moreover, cytoskeleton organization (RhoA signaling, ILK signaling), inflammation (IL-8 signaling), oxidative response, and differentiation (Tec kinase 
301 signalling, HGF and integrin signalling) were disrupted biological functions that accompanied Delta-24-RGD-mediated autophagy (figure 3D). Interestingly, deregulated proteins involved in protein synthesis (Ribosome biogenesis protein BOP1, 60S acidic ribosomal protein $\mathrm{P} 2$, 40S ribosomal protein S23) and DNA/RNA metabolism (TATAbinding protein-associated factor 2N, DNA-directed RNA polymerases I and III subunit RPAC1, DNA replication licensing factor MCM4, Cleavage stimulation factor subunit 3, and RNA-binding protein FUS) at $48 \mathrm{hpi}$, have been previously proposed as Delta-24RGD targets early in infection (26). To characterize in detail the glioma proteotype upon

Delta-24-RGD infection in the autophagic stage, we have performed proteome-scale interaction networks merging the 240 differential proteins detected in glioma-infected cells (48 hpi) (Figure 4). The protein interactome was mainly composed by specific protein clusters related to Poly(A) RNA binding, translation, mRNA splicing, and AMP metabolism. As shown in figure 4, Delta-24-RGD treatment directly affects the protein tyrosine kinase signalling, highly associated with glioblastoma oncogenesis (29).

\subsection{Activation state of predictive interactome hubs upon Delta-24-RGD infection}

316 We have applied a system biology approach to establish a framework to monitor

317 interaction between deregulated proteins and potential network modules that may be considered as protein targets to modulate the infectivity process. Akt and JNK appeared as functional interactors of part of the deregulated proteome (supplementary file 3), being activated during Delta-24-RGD mediated autophagy (9). As shown in figure 5, NFkB

321 also appeared as a hub in the differential interactome network. Subsequent experiments

322 were performed to monitor the activation state of this signal transducer late in infection 323 (Figure 5A). The increment in the serine 536 pohosphorylation of NFkB (24-48hpi) and

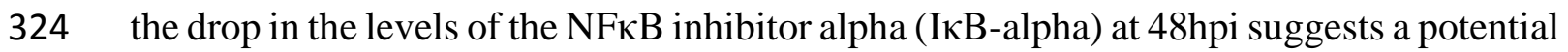
activation of this transcription factor. Previous studies point out that adenovirus infection 
326 induces the activation of $\mathrm{NF}-\mathrm{\kappa B}$ in cancer cell lines $(30,31)$, being associated with

327 resistance to different cell death and chemotherapeutic strategies in GBM (32), 328 suggesting that Delta-24-RGD-induced NF- $\kappa \mathrm{B}$ activation might be a protection 329 mechanism induced by glioma cells. PKC isozymes are overexpressed in astroglial brain 330 tumors (33). Our data indicate that Delta-24-RGD decreases PKC protein levels (Figure $3315 \mathrm{~B})$, probably restraining the hyperproliferative state and the invasive capacity of malignant glioma cells (34). Despite src kinase is also frequently activated in GBM, the use of specific inhibitory strategies has demonstrated a reduction in cell viability, and migration (35) as well as an induction of autophagic cell death in GBM cells (36). As shown in figure 5B, the essential phosphorylation of Y419 in the activation loop of c-src 336 (37), and total c-src levels were markedly reduced in glioma-infected cells at 48hpi 337 (Figure 5B). Moreover, Delta-24-RGD also affects the MAPK pathway, as suggested by 338 the down-regulation of ERK (Supplementary table 2) and its target MEK1/2 (figure 6A). All these data point out that Delta-24-RGD treatment directly interferes with signaling 340 pathways involved in cell growth, proliferation, adhesion, and migration. Due to the 341 reduction of PKA type 1a regulatory subunit (PRKAR1A) in Delta-24-RGD-infected 342 cells (Supplementary Table 2, network figure 6A), we focus our attention in the potential deregulation of PKA activation. As shown in figure 6A, an increment in phosphorylated

344 and total PKA levels was evidenced at 24hpi. Being PKA an E1A adenoviral protein 345 interactor, the co-overexpression of both proteins observed at 24hpi may contribute to 346 viral transcription, protein expression and progeny production (38). However, PKA 347 activation was reduced at $48 \mathrm{hpi}$ (figure 6A). This PKA inhibition was supported by the down-regulation of Ras GTPase-activating protein 1 (RASA1), an inhibitory regulator of the Ras-cyclic AMP pathway, that compromises cAMP generation. 
350 A growing body of evidences indicates that total and phosphorylated GSK-3 levels are increased in GBM, influencing its malignant phenotype (39). As shown in figure 6A, a dephosphorylation of GSK3 $\alpha / \beta$ was observed at $24 \mathrm{hpi}$, while GSK3 $\alpha / \beta$ protein levels

353 tend to be reduced at 48hpi. Although targeting of PKA and GSK-3 activity may result

354 in glioma conventional cell death (40-42), PKA inhibition and GSK-3 down-regulation could also contribute to Delta-24-RGD-induced autophagic flux in glioma cells $(27,43)$.

On the other hand, Delta-24-RGD also targeted serine/threonine protein phosphatase homeostasis in glioma cells late in infection. Specifically, Delta-24-RGD induced the overproduction of serine/threonine-protein phosphatase 6 catalytic subunit (PPP6C), PP4 regulatory subunit 3A (PPP4R3A) and PP1-beta catalytic subunit (PPP1CB) (Supplementary table 2). All of them have been previously related to glioblastoma invasion and recurrence (44). Figure $6 \mathrm{~B}$ shows the PP1/PP2A-regulated interactome modulated by Delta-24-RGD. Despite the slight PP1- $\alpha$ catalytic subunit activation (by dephosphorylation) observed at 24hpi in infected-glioma cells, Delta-24-RGD induced a decrease in PP1 $\alpha$ subunit and PP2A $\alpha / \beta$ catalytic subunit protein levels at $48 \mathrm{hpi}$ (figure 6B). Both S/T phosphatases are adenoviral E4orf4 protein interactors $(45,46)$ and cooperating partners in modulating the mitotic progression and tumor growth $(47,48)$, although a duality in the GBM field exists because PP2A inhibition or activation appear to be anti-oncogenic (44). Other protein that takes part in the PP1/PP2A-regulated

369 interactome, is calreticulin (CALR), which expression is induced during Delta-24-RGD infection (figure 6B, and supplementary table 2). Interestingly, this protein is a damageassociated molecular pattern (DAMP) molecule involved in the induction of antitumor immune response during antitumor therapy-induced autophagy $(49,50)$. 
376 Based on cerebrospinal fluid analysis derived from GBM patients, Delta-24-RGD therapy

377 alters the tumor microenvironment (51). Considering that the monitorization of cytokines

378

379 and growth factors specifically secreted by glioma cells to the tumor microenvironment may provide new insights into the modulation of the immune response induced by Delta24-RGD, we have performed a complementary secretome analysis of infected-glioma cells at 24 and 48hpi. Among the 80 secreted cell-cell signaling molecules analyzed, 14 were significantly increased in a time-dependent manner (Figure 7A). TGF-beta3 was significantly increased at 24 hpi whereas the chemotactic factor GRO (CXCL1), TIMP1, and TIMP-2 were up-regulated at 24-48 hpi. Other cytoquines such as GM-CSF, IL-8 (CXCL8), angiogenin, BLC (CXCL13), HGF, IGFBP-1, MIF, osteopontin, and osteoprotegerin (TNFRSF11B) were specifically overproduced at $48 \mathrm{hpi}$ (Figure 7A). Some of this cytokine and growth factors (GM-CSF, CXCL1, CXCL8, TIMP-1, TIMP2, TNFRSF11B) are targets of the NFאB complex. These data indicated that the cytokine secretion waves induced by Delta-24-RGD are highly dynamic and time-dependent during all phases of Delta-24-RGD viral cycle (26). To explore the cooperative action among differentially intracellular and extracellular molecules induced by Delta-24-RGD at $48 \mathrm{hpi}$, we have performed additional pathway analysis merging the proteomic dataset and the secretome information. As shown in figure 7B, Delta-24-RGD modulates pathways related to accumulation, migration, and activation of different inflammatory cells late in infection (supplementary table 4). It has been previously reported that Delta24-RGD induces a prolonged shift in the pro-tumoral M2 macrophages towards tumordetrimental phenotype as well as leukocyte recruitment and activation in GBM patients (51). All these data complement the notion that the immune system plays a fundamental role in the therapeutic efficacy of oncolytic Delta-24-RGD therapy of glioma (52-54). 


\section{Conclusion}

401 This work provides new insights regarding the molecular mechanisms governing the 402 glioma metabolism during Delta-24-RGD oncolytic adenoviral therapy. Although

403

404

405

406

407

408

409

410

411

412

413

414

415

416

417

418

419

420

421

422

423

424 additional experiments are needed to evaluate the effect of Delta-24-RGD in additional cell lines and in vivo models, the application of high-throughput proteomic approaches proves to be a useful tool to decipher the proteome expression profiles of glioma cells during antitumor therapy, and more importantly, to define potential therapeutic targets against GBM.

\section{Figure legends}

Figure 1. Spatio-temporal multi-omic approach applied throughout Delta-24-RGD Infection.

Figure 2. Rapid phospho-kinome response of Delta-24-RGD-infected cells during the first 30 minutes of infection. Phosphoproteome variations detected at 5, 15, and 30 mpi respect to mock-infected cells $(\mathrm{A}, \mathrm{C})$. Representative images of phospho-kinase arrays are shown $(\mathrm{B}, \mathrm{D})$.

\section{Figure 3. Differentially expressed proteins throughout late phases of Delta-24-RGD}

Infection. A) Expression of adenoviral proteins in glioma-infected cells. B) Volcano plot representing the fold-change of identified proteins with associated $\mathrm{P}$ values from the pairwise quantitative comparison of mock vs glioma-infected proteome at 48hpi (Left). In green, significantly down-regulated proteins, and in red, upregulated proteins $(\mathrm{P}<0.05)$. (C) Subcellular and (D) pathway distribution of the glioma proteome modulated by Delta24-RGD (48hpi).

Figure 4. Protein interactome network for Delta-24-RGD-modulated proteome. Network analysis was performed submitting the corresponding protein IDs to the 
425 STRING (Search Tool for the Retrieval of Interacting Genes) software (v.10.5)

426 (http://stringdb.org/). Proteins are represented with nodes and the interactions with

427 continuous lines to represent direct interactions (physical), while indirect ones

428 (functional) are presented by interrupted lines. All the edges were supported by at least a

429 reference from the literature or from canonical information stored in the STRING

430 database. To minimize false positives as well as false negatives, only interactions tagged

as "high confidence" $(>0.7)$ in STRING database were considered. K means clustering was applied.

Figure 5. Delta-24-RGD-modulated proteome is functionally related with NFkB,

SRC, and PKC. Specific protein interactomes modulated by Delta-24-RGD in glioma cells late in infection (48hpi) (down- and up-regulated proteins in Delta-24-RGD-infected glioma cells in green and red respectively). Levels and residue-specific phosphorylation

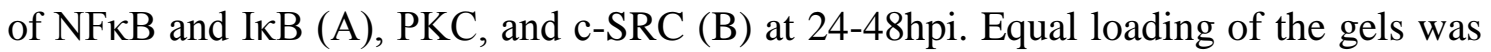
assessed by Ponceau staining and band intensities were normalized to total stain in each gel lane. Representative Western blot images from three independent experiments are 440 shown.

Figure 6. Delta-24-RGD induces specific signaling derangements late in infection.

Specific kinase-regulated interactomes modulated by Delta-24-RGD in glioma cells at 48hpi (down- and up-regulated proteins in Delta-24-RGD-infected glioma cells in green and red respectively). Levels and residue-specific phosphorylation of PKAc, MEK1/2, and GSK3- $\square / \square$ (A), PP1 $\alpha$, and PP2A $\checkmark / \propto$ (B) at 24-48hpi. Equal loading of the gels was assessed by Ponceau staining and band intensities were normalized to total stain in each gel lane. Representative Western blot images from three independent experiments are shown. 
450 of glioma cells. A time-dependent analysis of 80 cytokines/growth factors was performed 451 in the cell media of mock-infected glioma cells and glioma-infected cells (24, and 48hpi) 452 using a dot-blot protein array method. Three independent experiments were performed. 453 Data are presented as mean \pm SEM. $* \mathrm{p}<0.05,{ }^{*} * \mathrm{p}<0.01$, and $* * * \mathrm{p}<0.001$ vs mock454 infected condition (A). Pathway mapping of intracellular deregulated proteins and the 455 differential secretome obtained by IPA software (supplementary table 4) (B).

\section{Supporting information}

457 Additional file 1. Glioma proteome quantitation in Delta-24-RGD-infected cells (48hpi).

458 Additional file 2. Delta24RGD-modulated proteome in infected-glioma cells (48hpi).

459 Additional file 3. Protein interactomes deregulated by Delta-24-RGD. Akt and c-Jun 460 activation late in infection.

461 Additional file 4. Pathway mapping of intracellular and extracellular proteins 462 differentially expressed upon Delta-24-RGD infection.

463

464 Acknowledgements

465 This work was funded by grants from the Spanish Ministry of Economy and 466 Competitiveness (MINECO) (Ref. SAF2014-59340-R To ES), the Department of 467 Economic Development from Government of Navarra (Ref. PC023-PC024, PC025, 468 PC081-82 and PI059 to ES and PI031 to JFI), the Instituto de Salud Carlos III and Fondos 469 Feder Europeos (PI16/00066 to MMA), the Spanish Ministry of Science and Innovation 470 (IEDI-2015-00638 to MMA), the Department of Health of the Government of Navarra 471 (to MMA), the Basque Foundation for Health Research (BIOEF, BIO13/CI/005 to 472 MMA), Asociación Pablo Ugarte-Fuerza, Julen (to MMA). AGM was supported by PEJ473 2014-A-61949 (MINECO). Authors thank all PRIDE Team for helping with the mass 
475 Navarrabiomed is a member of Proteored, PRB3-ISCIII, and is supported by grant

PT17/0019/0009, of the PE I+D+I 2013-2016 funded by ISCIII and FEDER.

477

\section{References}

479

1. Fueyo, J., Alemany, R., Gomez-Manzano, C., Fuller, G. N., Khan, A., Conrad, C.

480

481

482

483

484

485

486

487

488

489

490

491

492

493

494

495

496

497

498

499

500

501

502

503

504

505

506

507

508

509

510

511

512

513

514

515

6. Jiang, H., Gomez-Manzano, C., Lang, F. F., Alemany, R., and Fueyo, J. (2009) A., Liu, T. J., Jiang, H., Lemoine, M. G., Suzuki, K., Sawaya, R., Curiel, D. T., Yung, W. K., and Lang, F. F. (2003) Preclinical characterization of the antiglioma activity of a tropism-enhanced adenovirus targeted to the retinoblastoma pathway, J Natl Cancer Inst 95, 652-660.

2. Fueyo, J., Gomez-Manzano, C., Alemany, R., Lee, P. S., McDonnell, T. J., Mitlianga, P., Shi, Y. X., Levin, V. A., Yung, W. K., and Kyritsis, A. P. (2000) A mutant oncolytic adenovirus targeting the $\mathrm{Rb}$ pathway produces anti-glioma effect in vivo, Oncogene 19, 2-12.

3. Suzuki, K., Fueyo, J., Krasnykh, V., Reynolds, P. N., Curiel, D. T., and Alemany, R. (2001) A conditionally replicative adenovirus with enhanced infectivity shows improved oncolytic potency, Clin Cancer Res 7, 120-126.

4. Jiang, H., Clise-Dwyer, K., Ruisaard, K. E., Fan, X., Tian, W., Gumin, J., Lamfers, M. L., Kleijn, A., Lang, F. F., Yung, W. K., Vence, L. M., Gomez-Manzano, C., and Fueyo, J. (2014) Delta-24-RGD oncolytic adenovirus elicits anti-glioma immunity in an immunocompetent mouse model, PLoS One 9, e97407.

5. Jiang, H., Gomez-Manzano, C., Aoki, H., Alonso, M. M., Kondo, S., McCormick, F., Xu, J., Kondo, Y., Bekele, B. N., Colman, H., Lang, F. F., and Fueyo, J. (2007) Examination of the therapeutic potential of Delta-24-RGD in brain tumor stem cells: role of autophagic cell death, J Nat/ Cancer Inst 99, 1410-1414.

Oncolytic adenovirus: preclinical and clinical studies in patients with human malignant gliomas, Curr Gene Ther 9, 422-427.

7. Tejada, S., Alonso, M., Patino, A., Fueyo, J., Gomez-Manzano, C., and Diez-Valle, R. (2017) Phase I Trial of DNX-2401 for Diffuse Intrinsic Pontine Glioma Newly Diagnosed in Pediatric Patients, Neurosurgery.

8. Lang, F. F., Conrad, C., Gomez-Manzano, C., Yung, W. K. A., Sawaya, R., Weinberg, J. S., Prabhu, S. S., Rao, G., Fuller, G. N., Aldape, K. D., Gumin, J., Vence, L. M., Wistuba, I., Rodriguez-Canales, J., Villalobos, P. A., Dirven, C. M. F., Tejada, S., Valle, R. D., Alonso, M. M., Ewald, B., Peterkin, J. J., Tufaro, F., and Fueyo, J. Phase I Study of DNX-2401 (Delta-24-RGD) Oncolytic Adenovirus: Replication and Immunotherapeutic Effects in Recurrent Malignant Glioma, J Clin Oncol 36, 1419-1427.

9. Klein, S. R., Piya, S., Lu, Z., Xia, Y., Alonso, M. M., White, E. J., Wei, J., GomezManzano, C., Jiang, H., and Fueyo, J. (2015) C-Jun N-terminal kinases are required for oncolytic adenovirus-mediated autophagy, Oncogene 34, 52955301. 
10. Ito, H., Aoki, H., Kuhnel, F., Kondo, Y., Kubicka, S., Wirth, T., Iwado, E., Iwamaru, A., Fujiwara, K., Hess, K. R., Lang, F. F., Sawaya, R., and Kondo, S. (2006) Autophagic cell death of malignant glioma cells induced by a conditionally replicating adenovirus, J Natl Cancer Inst 98, 625-636.

11. Jiang, H., White, E. J., Gomez-Manzano, C., and Fueyo, J. (2008) Adenovirus's last trick: you say lysis, we say autophagy, Autophagy 4, 118-120.

12. Jiang, H., White, E. J., Rios-Vicil, C. I., Xu, J., Gomez-Manzano, C., and Fueyo, J. (2011) Human adenovirus type 5 induces cell lysis through autophagy and autophagy-triggered caspase activity, J Virol 85, 4720-4729.

13. Piya, S., White, E. J., Klein, S. R., Jiang, H., McDonnell, T. J., Gomez-Manzano, C., and Fueyo, J. (2011) The E1B19K oncoprotein complexes with Beclin 1 to regulate autophagy in adenovirus-infected cells, PLoS One 6, e29467.

14. Bianco, J., Bastiancich, C., Jankovski, A., des Rieux, A., Preat, V., and Danhier, F. (2017) On glioblastoma and the search for a cure: where do we stand?, Cell Mol Life Sci 74, 2451-2466.

15. Lawler, S. E., Speranza, M. C., Cho, C. F., and Chiocca, E. A. Oncolytic Viruses in Cancer Treatment: A Review, JAMA Oncol 3, 841-849.

16. Panek, W. K., Kane, J. R., Young, J. S., Rashidi, A., Kim, J. W., Kanojia, D., and Lesniak, M. S. Hitting the nail on the head: combining oncolytic adenovirusmediated virotherapy and immunomodulation for the treatment of glioma, Oncotarget 8, 89391-89405.

17. Vitari, A. C., Deak, M., Collins, B. J., Morrice, N., Prescott, A. R., Phelan, A., Humphreys, S., and Alessi, D. R. (2004) WNK1, the kinase mutated in an inherited high-blood-pressure syndrome, is a novel PKB (protein kinase B)/Akt substrate, Biochem J 378, 257-268.

18. Choate, K. A., Kahle, K. T., Wilson, F. H., Nelson-Williams, C., and Lifton, R. P. (2003) WNK1, a kinase mutated in inherited hypertension with hyperkalemia, localizes to diverse $\mathrm{Cl}$ - -transporting epithelia, Proc Natl Acad Sci U S A 100, 663-668.

19. Zhu, W., Begum, G., Pointer, K., Clark, P. A., Yang, S. S., Lin, S. H., Kahle, K. T., Kuo, J. S., and Sun, D. WNK1-OSR1 kinase-mediated phospho-activation of Na+$\mathrm{K}+-2 \mathrm{Cl}$ - cotransporter facilitates glioma migration, Mol Cancer 13, 31.

20. Alonso, M. M., Gomez-Manzano, C., Bekele, B. N., Yung, W. K., and Fueyo, J. (2007) Adenovirus-based strategies overcome temozolomide resistance by silencing the 06-methylguanine-DNA methyltransferase promoter, Cancer Res 67, 11499-11504.

21. Hibi, M., Lin, A., Smeal, T., Minden, A., and Karin, M. (1993) Identification of an oncoprotein- and UV-responsive protein kinase that binds and potentiates the c-Jun activation domain, Genes Dev 7, 2135-2148.

22. Derijard, B., Hibi, M., Wu, I. H., Barrett, T., Su, B., Deng, T., Karin, M., and Davis, R. J. (1994) JNK1: a protein kinase stimulated by UV light and Ha-Ras that binds and phosphorylates the c-Jun activation domain, Cell 76, 1025-1037.

23. Cho, Y. Y., Tang, F., Yao, K., Lu, C., Zhu, F., Zheng, D., Pugliese, A., Bode, A. M., and Dong, Z. (2009) Cyclin-dependent kinase-3-mediated c-Jun phosphorylation at Ser63 and Ser73 enhances cell transformation, Cancer Res 69, 272-281. 
600

601

602

603

604

605

24. Blaszczyk, K., Nowicka, H., Kostyrko, K., Antonczyk, A., Wesoly, J., and Bluyssen, $\mathrm{H}$. A. The unique role of STAT2 in constitutive and IFN-induced transcription and antiviral responses, Cytokine Growth Factor Rev 29, 71-81.

25. Liang, Y., Diehn, M., Watson, N., Bollen, A. W., Aldape, K. D., Nicholas, M. K., Lamborn, K. R., Berger, M. S., Botstein, D., Brown, P. O., and Israel, M. A. (2005) Gene expression profiling reveals molecularly and clinically distinct subtypes of glioblastoma multiforme, Proc Natl Acad Sci U S A 102, 5814-5819.

26. Gonzalez-Morales, A., Zabaleta, A., Guruceaga, E., Alonso, M. M., GarciaMoure, M., Fernandez-Irigoyen, J., and Santamaria, E. Spatial and temporal proteome dynamics of glioma cells during oncolytic adenovirus Delta-24-RGD infection, Oncotarget 9, 31045-31065.

27. He, C., and Klionsky, D. J. (2009) Regulation mechanisms and signaling pathways of autophagy, Annu Rev Genet 43, 67-93.

28. Tazawa, H., Kuroda, S., Hasei, J., Kagawa, S., and Fujiwara, T. Impact of Autophagy in Oncolytic Adenoviral Therapy for Cancer, Int J Mol Sci 18.

29. Wick, W., Weller, M., Weiler, M., Batchelor, T., Yung, A. W., and Platten, M. Pathway inhibition: emerging molecular targets for treating glioblastoma, Neuro Oncol 13, 566-579.

30. Hodzic, J., Sie, D., Vermeulen, A., and van Beusechem, V. W. (2017) Functional Screening Identifies Human miRNAs that Modulate Adenovirus Propagation in Prostate Cancer Cells, Hum Gene Ther 28, 766-780.

31. Palmer, D. H., Chen, M. J., Searle, P. F., Kerr, D. J., and Young, L. S. (2005) Inhibition of NF-kappaB enhances the cytotoxicity of virus-directed enzyme prodrug therapy and oncolytic adenovirus cancer gene therapy, Gene Ther 12, 1187-1197.

32. Nogueira, L., Ruiz-Ontanon, P., Vazquez-Barquero, A., Moris, F., and FernandezLuna, J. L. (2011) The NFkappaB pathway: a therapeutic target in glioblastoma, Oncotarget 2, 646-653.

33. Sharif, T. R., and Sharif, M. (1999) Overexpression of protein kinase C epsilon in astroglial brain tumor derived cell lines and primary tumor samples, Int J Oncol 15, 237-243.

34. da Rocha, A. B., Mans, D. R., Regner, A., and Schwartsmann, G. (2002) Targeting protein kinase $C$ : new therapeutic opportunities against high-grade malignant gliomas?, Oncologist 7, 17-33.

35. Du, J., Bernasconi, P., Clauser, K. R., Mani, D. R., Finn, S. P., Beroukhim, R., Burns, M., Julian, B., Peng, X. P., Hieronymus, H., Maglathlin, R. L., Lewis, T. A., Liau, L. M., Nghiemphu, P., Mellinghoff, I. K., Louis, D. N., Loda, M., Carr, S. A., Kung, A. L., and Golub, T. R. (2009) Bead-based profiling of tyrosine kinase phosphorylation identifies SRC as a potential target for glioblastoma therapy, Nat Biotechnol 27, 77-83.

36. Milano, V., Piao, Y., LaFortune, T., and de Groot, J. (2009) Dasatinib-induced autophagy is enhanced in combination with temozolomide in glioma, $\mathrm{Mol}$ Cancer Ther 8, 394-406.

37. Roskoski, R., Jr. (2005) Src kinase regulation by phosphorylation and dephosphorylation, Biochem Biophys Res Commun 331, 1-14. 
38. King, C. R., Cohen, M. J., Fonseca, G. J., Dirk, B. S., Dikeakos, J. D., and Mymryk, J. S. Functional and Structural Mimicry of Cellular Protein Kinase A Anchoring Proteins by a Viral Oncoprotein, PLoS Pathog 12, e1005621.

39. Majewska, E., and Szeliga, M. AKT/GSK3beta Signaling in Glioblastoma, Neurochem Res 42, 918-924.

40. Mucignat-Caretta, C., Denaro, L., D'Avella, D., and Caretta, A. Protein Kinase A Distribution Differentiates Human Glioblastoma from Brain Tissue, Cancers (Basel) 10.

41. Miyashita, K., Kawakami, K., Nakada, M., Mai, W., Shakoori, A., Fujisawa, H., Hayashi, Y., Hamada, J., and Minamoto, T. (2009) Potential therapeutic effect of glycogen synthase kinase 3 beta inhibition against human glioblastoma, Clin Cancer Res 15, 887-897.

42. Kotliarova, S., Pastorino, S., Kovell, L. C., Kotliarov, Y., Song, H., Zhang, W., Bailey, R., Maric, D., Zenklusen, J. C., Lee, J., and Fine, H. A. (2008) Glycogen synthase kinase-3 inhibition induces glioma cell death through c-MYC, nuclear factor-kappaB, and glucose regulation, Cancer Res 68, 6643-6651.

43. Ren, J., Liu, T., Han, Y., Wang, Q., Chen, Y., Li, G., and Jiang, L. GSK-3beta inhibits autophagy and enhances radiosensitivity in non-small cell lung cancer, Diagn Pathol 13, 33.

44. Dedobbeleer, M., Willems, E., Freeman, S., Lombard, A., Goffart, N., and Rogister, B. Phosphatases and solid tumors: focus on glioblastoma initiation, progression and recurrences, Biochem J 474, 2903-2924.

45. Mui, M. Z., Kucharski, M., Miron, M. J., Hur, W. S., Berghuis, A. M., Blanchette, $\mathrm{P}$., and Branton, P. E. Identification of the adenovirus E4orf4 protein binding site on the B55alpha and Cdc55 regulatory subunits of PP2A: Implications for PP2A function, tumor cell killing and viral replication, PLoS Pathog 9, e1003742.

46. Mui, M. Z., Zhou, Y., Blanchette, P., Chughtai, N., Knight, J. F., Gruosso, T., Papadakis, A. I., Huang, S., Park, M., Gingras, A. C., and Branton, P. E. The Human Adenovirus Type 5 E4orf4 Protein Targets Two Phosphatase Regulators of the Hippo Signaling Pathway, J Virol 89, 8855-8870.

47. Grallert, A., Boke, E., Hagting, A., Hodgson, B., Connolly, Y., Griffiths, J. R., Smith, D. L., Pines, J., and Hagan, I. M. A PP1-PP2A phosphatase relay controls mitotic progression, Nature 517, 94-98.

48. Kolupaeva, V., and Janssens, V. PP1 and PP2A phosphatases--cooperating partners in modulating retinoblastoma protein activation, FEBS J 280, 627-643.

49. Zelenay, S., and Reis e Sousa, C. Adaptive immunity after cell death, Trends Immunol 34, 329-335.

50. Shibutani, S. T., Saitoh, T., Nowag, H., Munz, C., and Yoshimori, T. Autophagy and autophagy-related proteins in the immune system, Nat Immunol 16, 10141024.

51. van den Bossche, W. B. L., Kleijn, A., Teunissen, C. E., Voerman, J. S. A., Teodosio, C., Noske, D. P., van Dongen, J. J. M., Dirven, C. M. F., and Lamfers, M. L. M. Oncolytic virotherapy in glioblastoma patients induces a tumor macrophage phenotypic shift leading to an altered glioblastoma microenvironment, Neuro Oncol.

52. Jiang, H., and Fueyo, J. (2014) Healing after death: antitumor immunity induced by oncolytic adenoviral therapy, Oncoimmunology 3, e947872. 
53. Jiang, H., Rivera-Molina, Y., Gomez-Manzano, C., Clise-Dwyer, K., Bover, L., Vence, L. M., Yuan, Y., Lang, F. F., Toniatti, C., Hossain, M. B., and Fueyo, J. (2017) Oncolytic Adenovirus and Tumor-Targeting Immune Modulatory Therapy Improve Autologous Cancer Vaccination, Cancer Res 77, 3894-3907.

54. Kleijn, A., Kloezeman, J., Treffers-Westerlaken, E., Fulci, G., Leenstra, S., Dirven, C., Debets, R., and Lamfers, M. (2014) The in vivo therapeutic efficacy of the oncolytic adenovirus Delta24-RGD is mediated by tumor-specific immunity, PLoS One 9, e97495.

55. Vizcaino, J. A., Deutsch, E. W., Wang, R., Csordas, A., Reisinger, F., Rios, D., Dianes, J. A., Sun, Z., Farrah, T., Bandeira, N., Binz, P. A., Xenarios, I., Eisenacher, M., Mayer, G., Gatto, L., Campos, A., Chalkley, R. J., Kraus, H. J., Albar, J. P., Martinez-Bartolome, S., Apweiler, R., Omenn, G. S., Martens, L., Jones, A. R., and Hermjakob, H. (2014) ProteomeXchange provides globally coordinated proteomics data submission and dissemination, Nat Biotechnol 32, 223-226.

56. Szklarczyk, D., Morris, J. H., Cook, H., Kuhn, M., Wyder, S., Simonovic, M., Santos, A., Doncheva, N. T., Roth, A., Bork, P., Jensen, L. J., and von Mering, C. The STRING database in 2017: quality-controlled protein-protein association networks, made broadly accessible, Nucleic Acids Res 45, D362-D368.

57. Tyanova, S., Temu, T., Sinitcyn, P., Carlson, A., Hein, M. Y., Geiger, T., Mann, M., and Cox, J. The Perseus computational platform for comprehensive analysis of (prote)omics data, Nat Methods 13, 731-740.

58. Moritz, C. P. Tubulin or Not Tubulin: Heading Toward Total Protein Staining as Loading Control in Western Blots, Proteomics 17. 

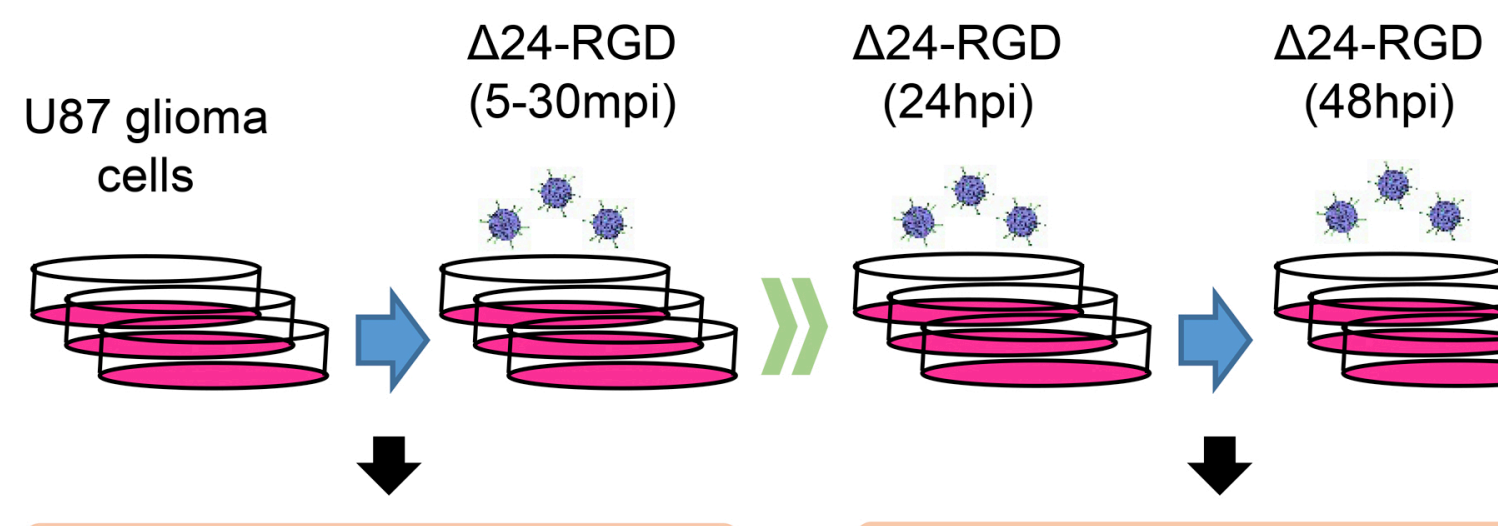

Viral internalization

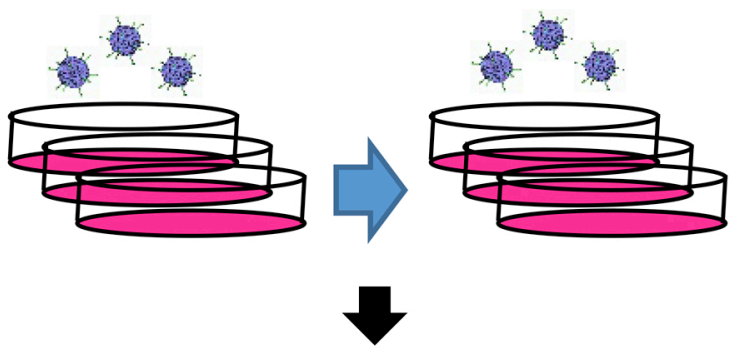

\section{Autophagy}

Phosphoproteomics

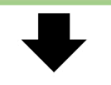

Signaling dynamics

$(5,15,30 \mathrm{mpi})$

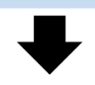

Spatial quantitative proteomics

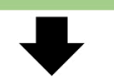

Secretome intracellular

(24 \& 48hpi)

Protein interaction networks \& Pathway analysis

Validation \& functional assays 
A

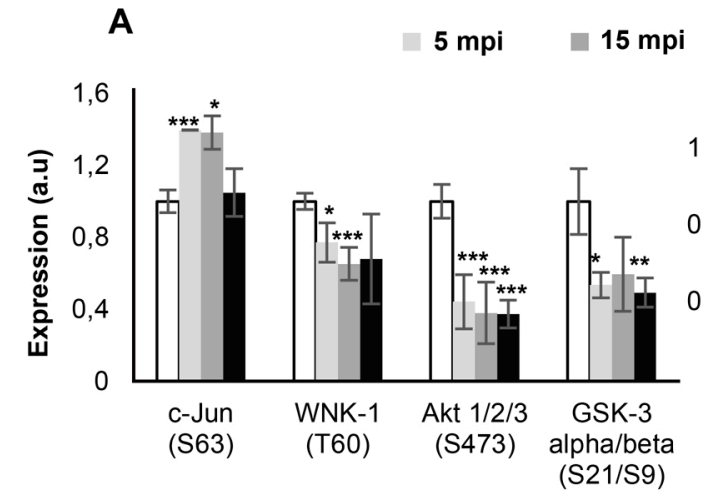

C
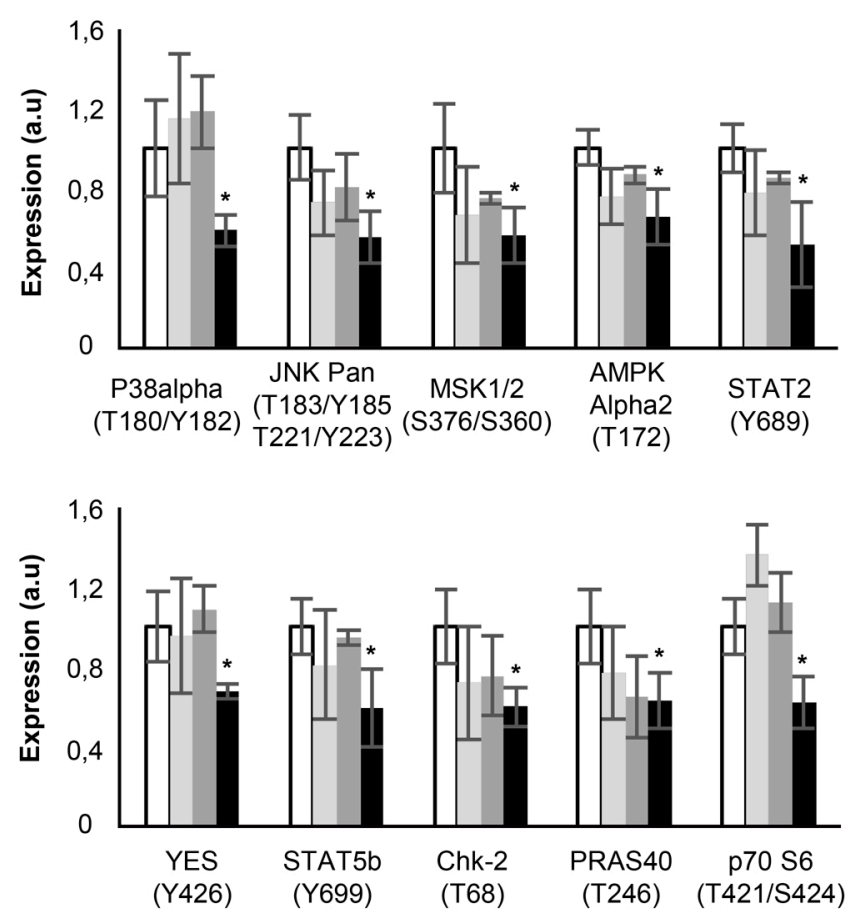

B

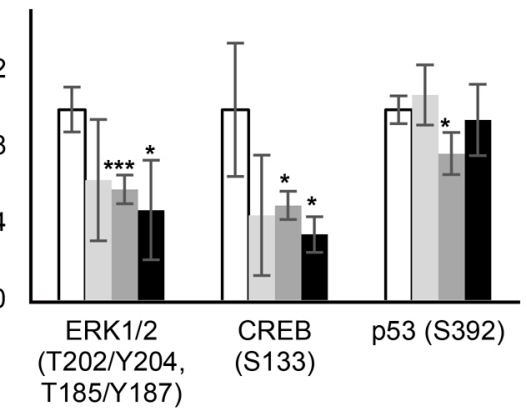

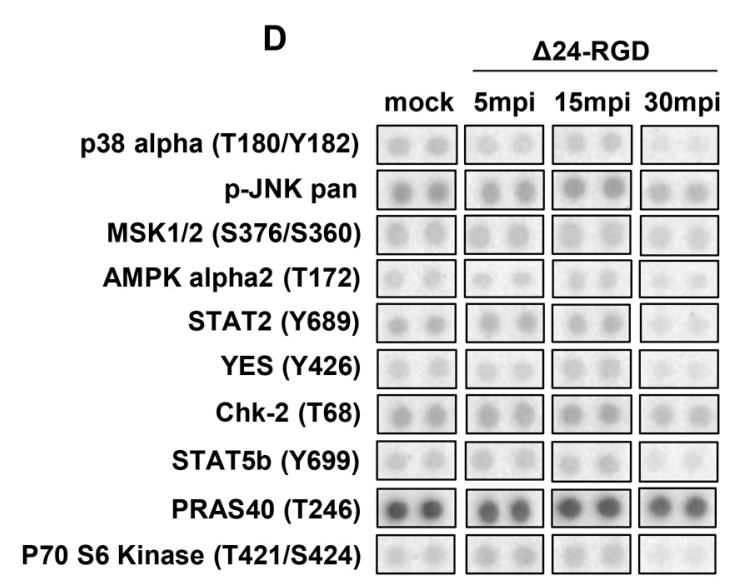

GSK-3 (S21/S9)

ERK1/2 (T202/Y204)

CREB (S133)

p53 (S392)

mock $5 \mathrm{mpi} 15 \mathrm{mpi} 30 \mathrm{mpi}$

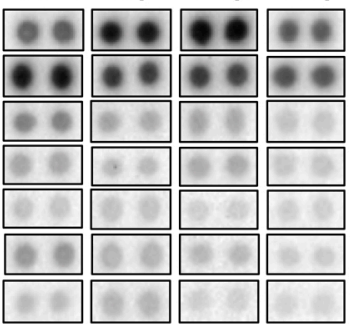

P70 S6 Kinase (T421/S424) 


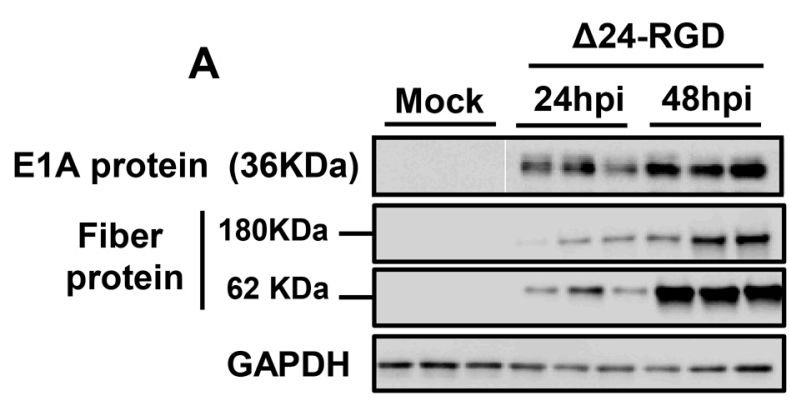

B
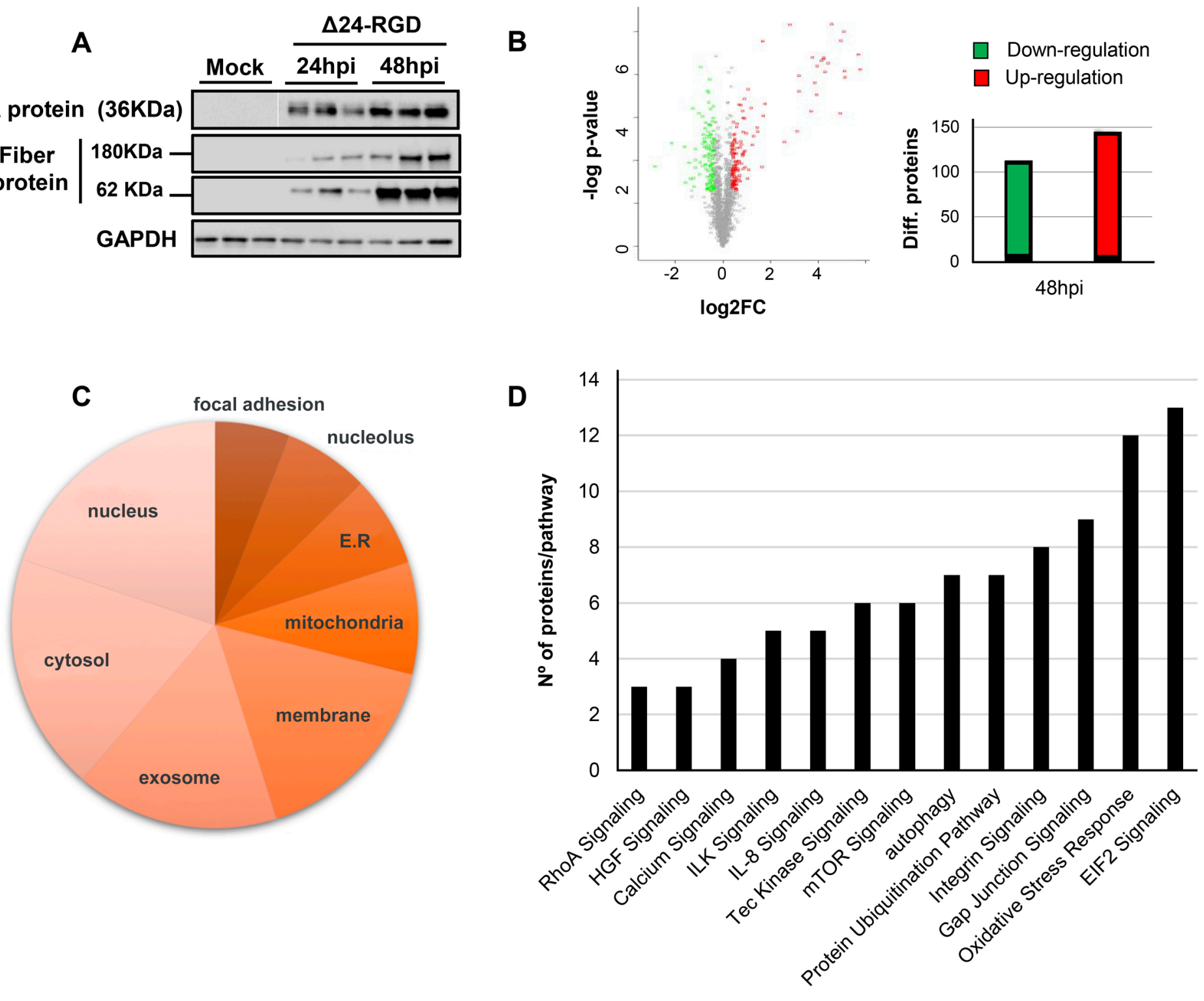


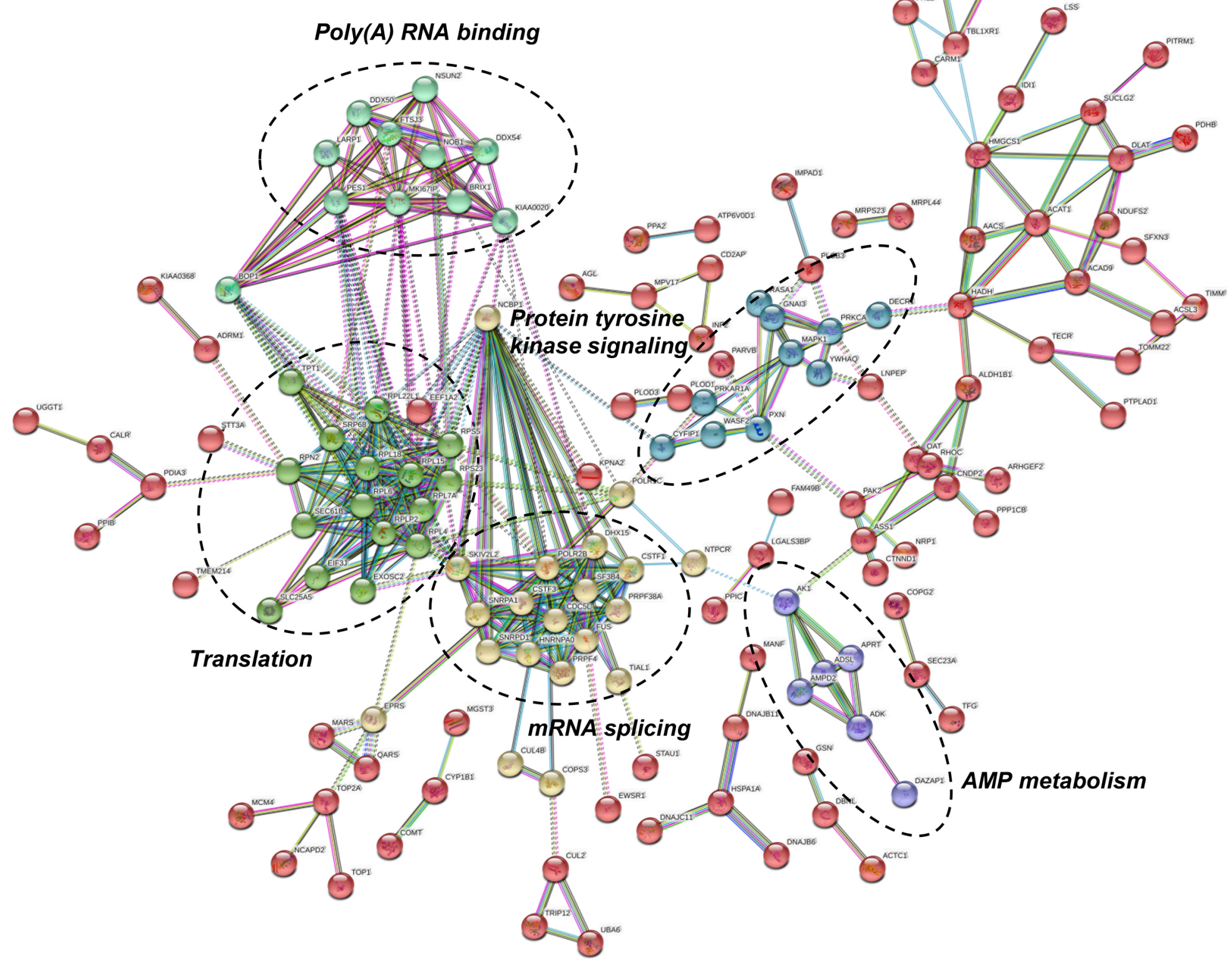


A
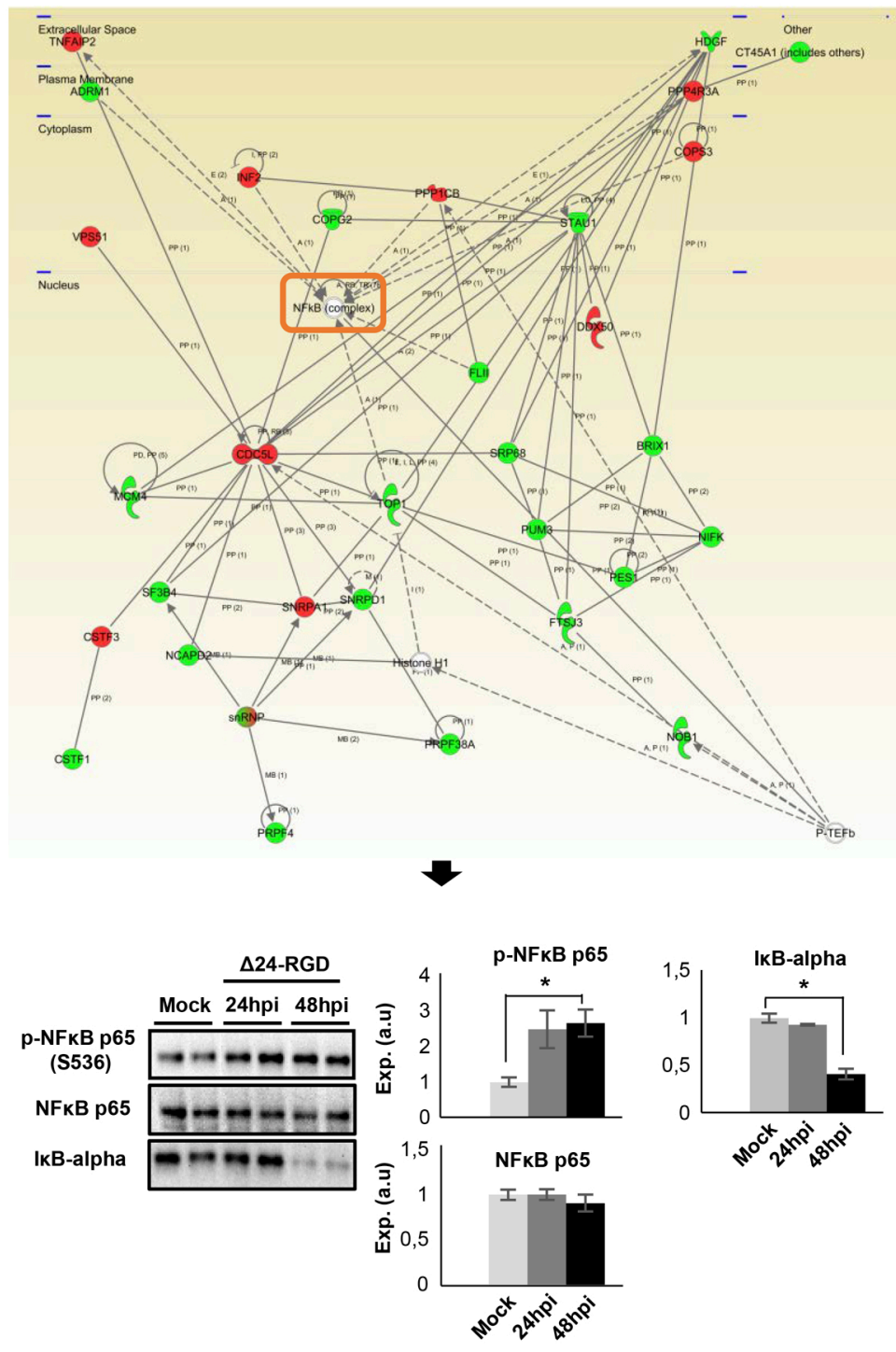

B
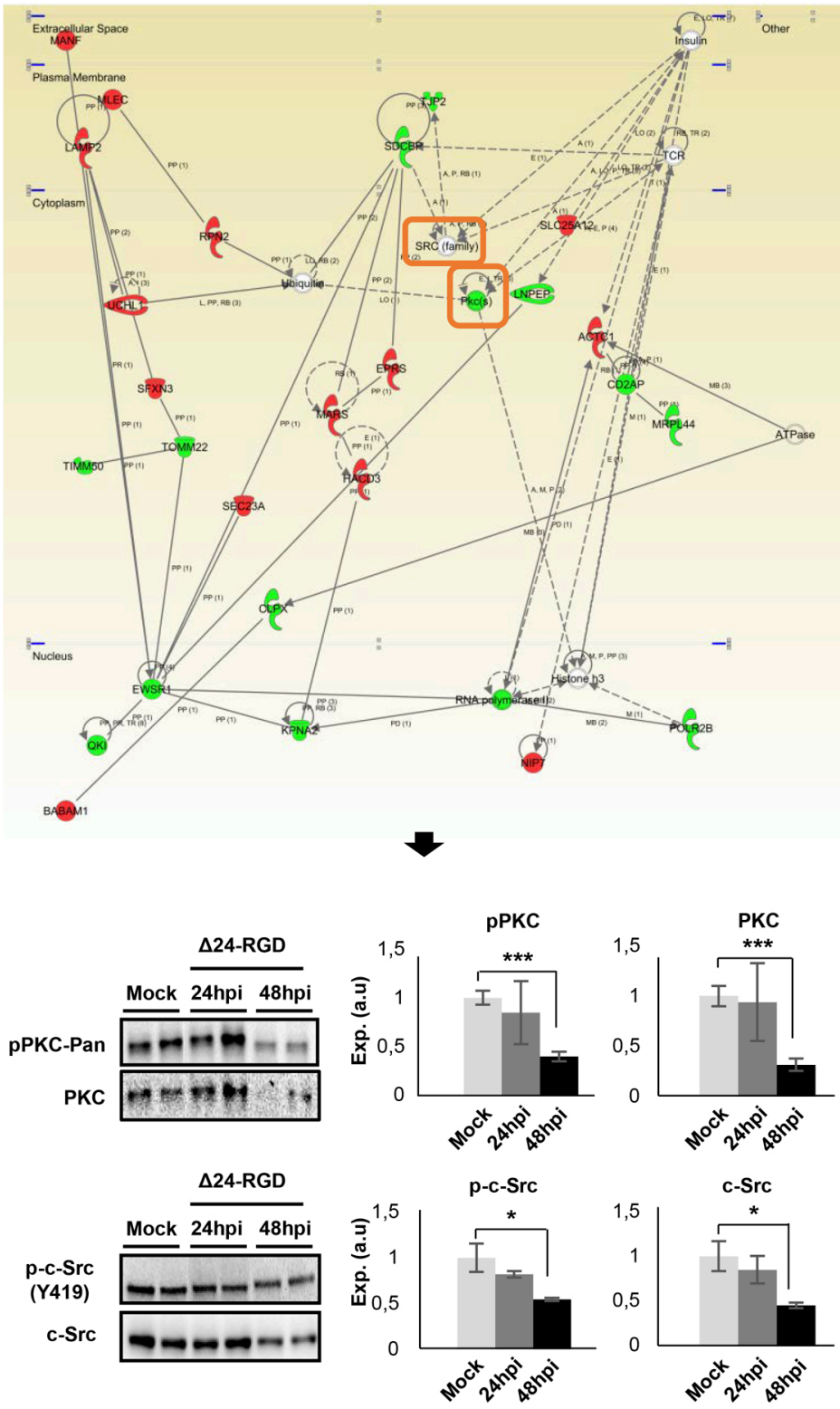
A

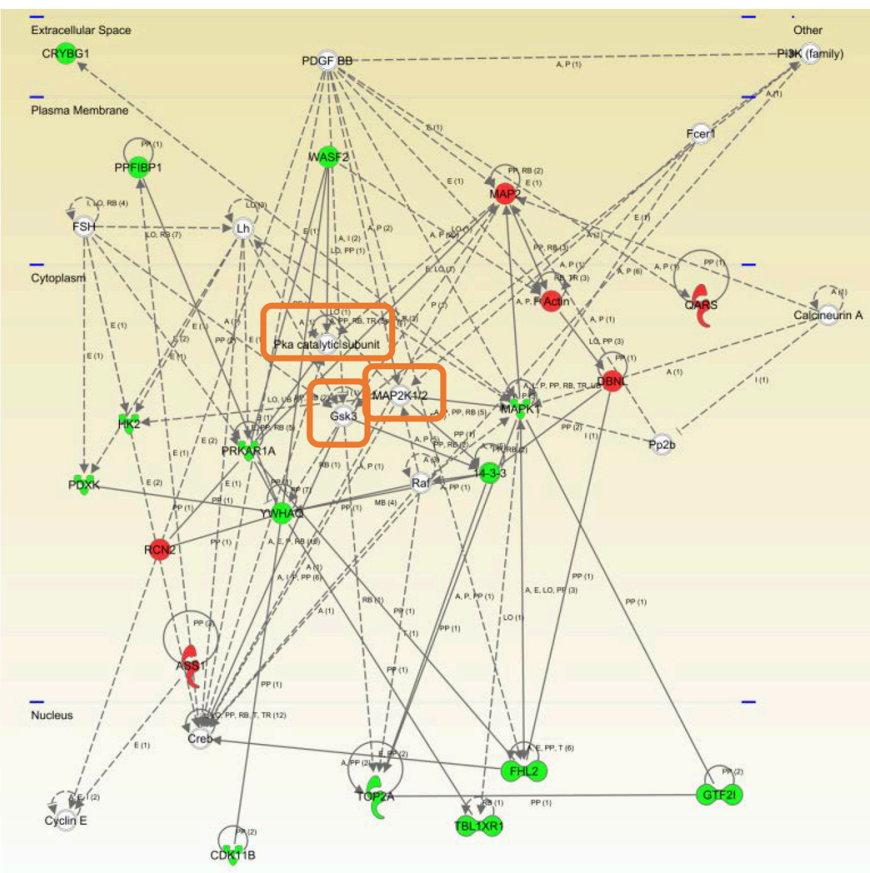

$\Delta 24-R G D$
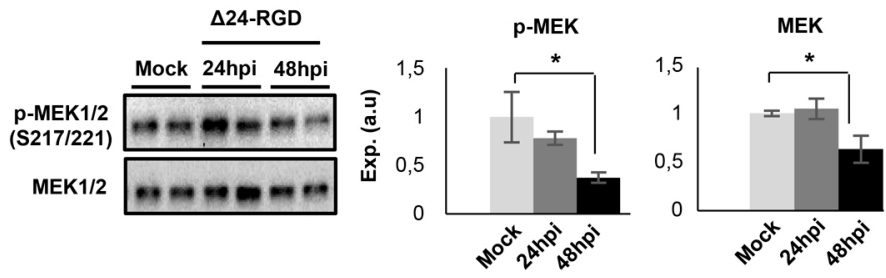

D24-RGD
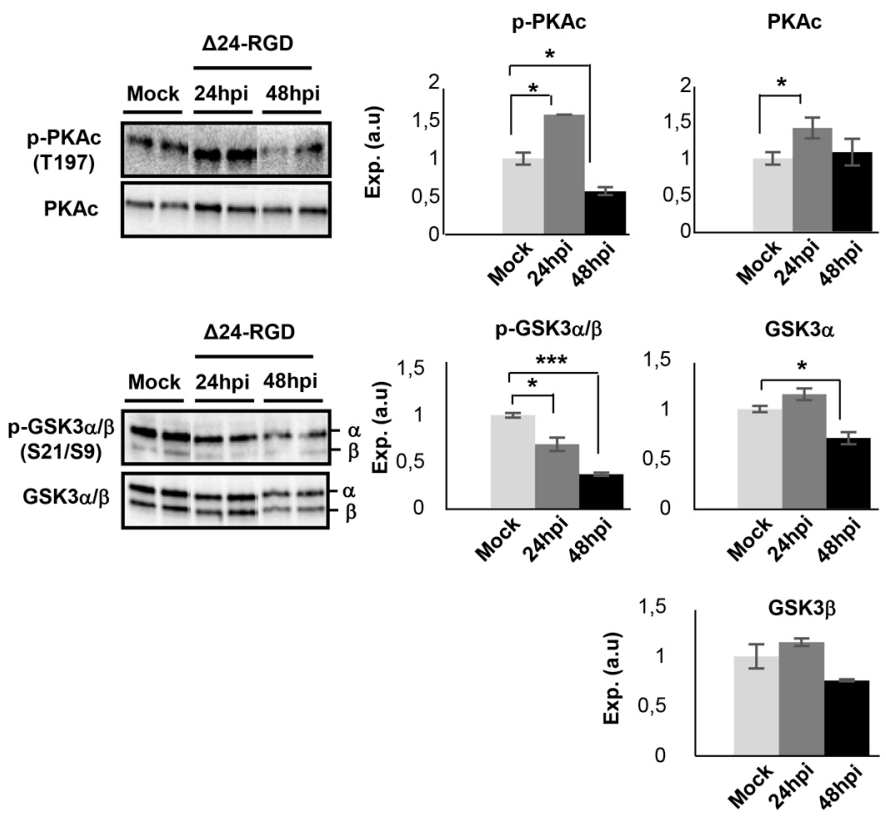

B
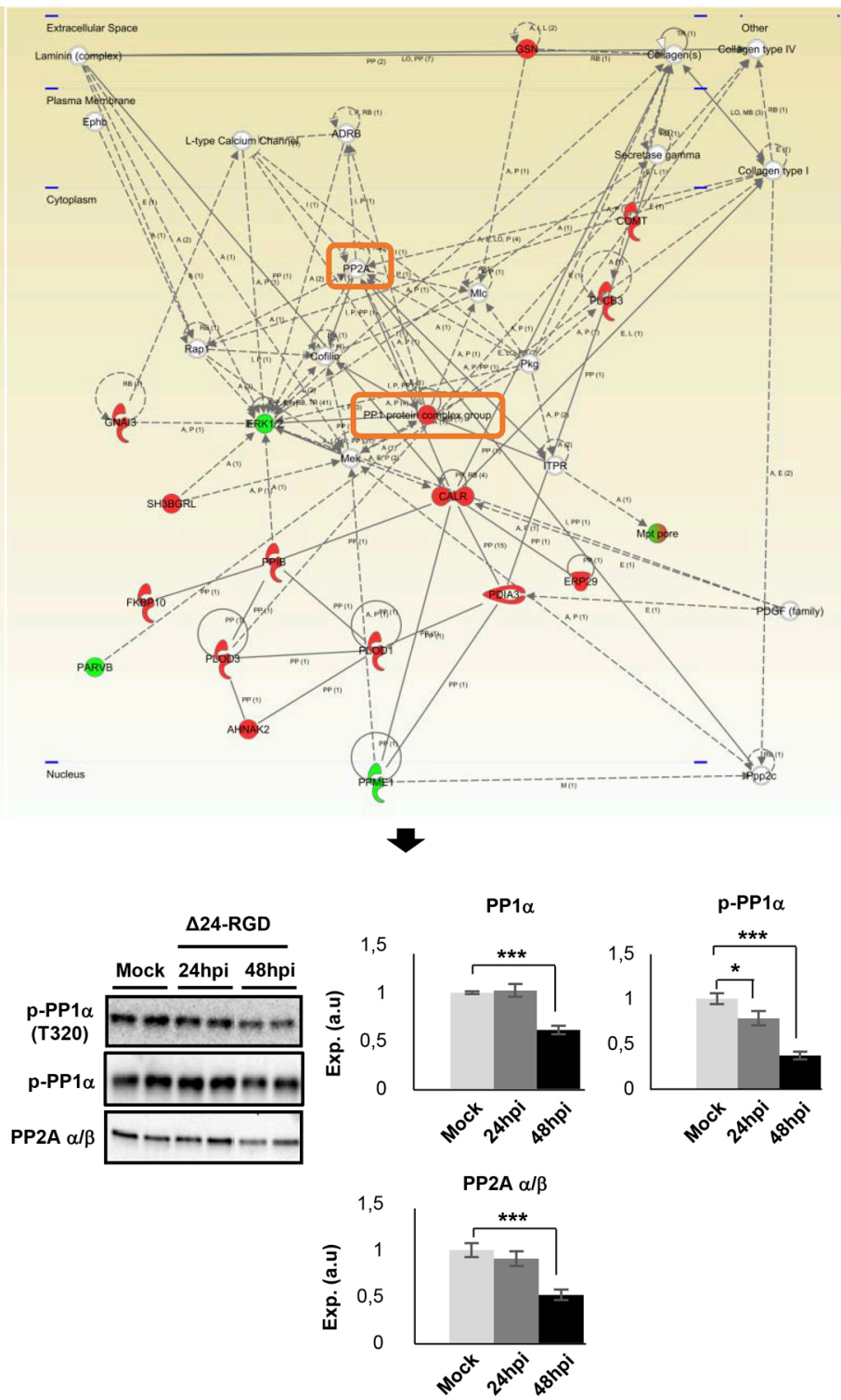
A
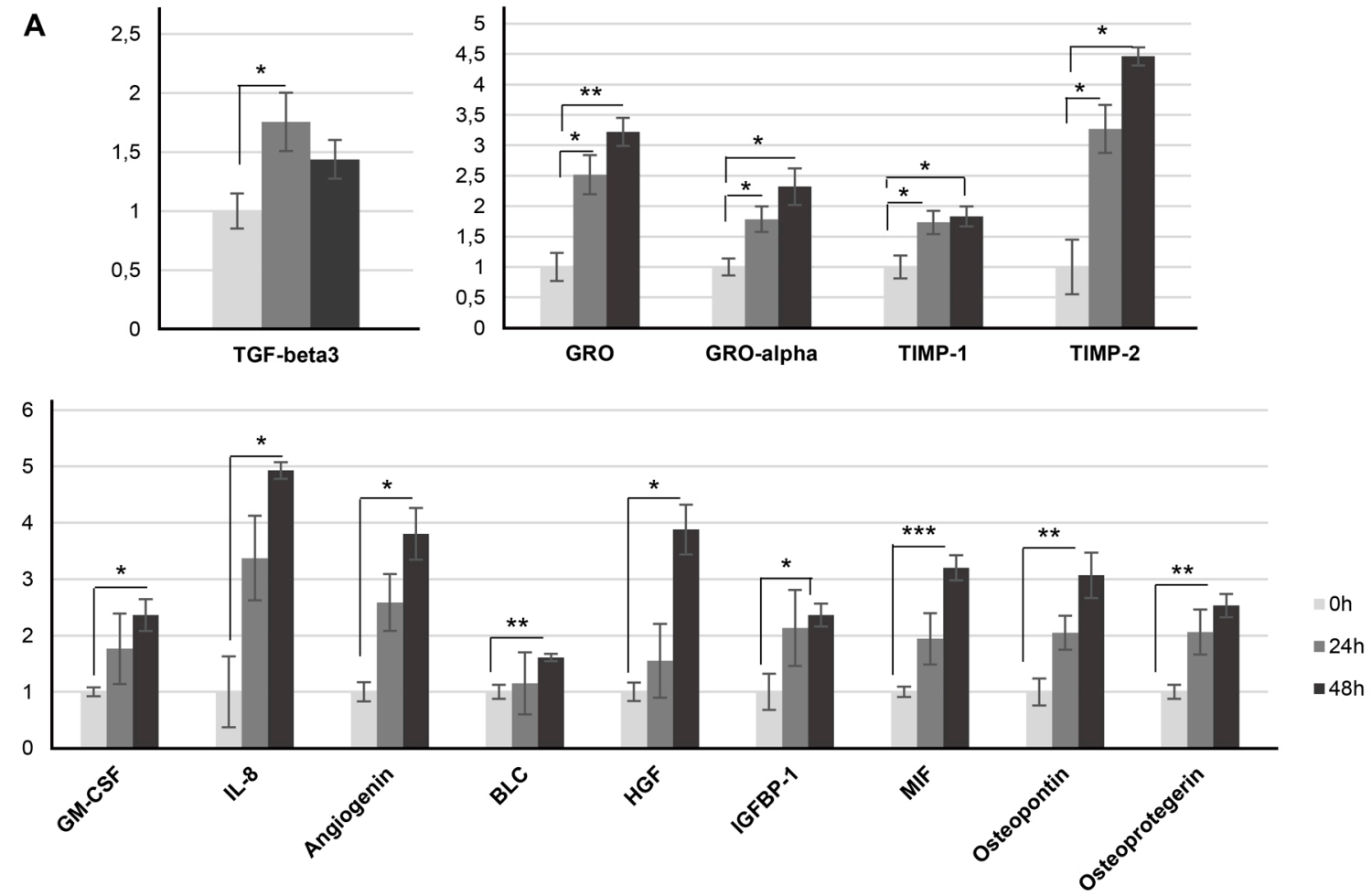

B

Migration of mononuclear leukocytes Lymphocyte migration Migration of phagocytes Response of phagocytes Response of myeloid cells Migration of fibroblast cell lines

Engulfment of myeloid cells Accumulation of phagocytes

Activation of granulocytes

Phagocytosis by macrophages

Leukocytosis

Activation of neutrophils

Binding of NFkB binding site

Chemotaxis of leukocyte cell lines

Accumulation of neutrophils Transmigration of mononuclear leukocytes

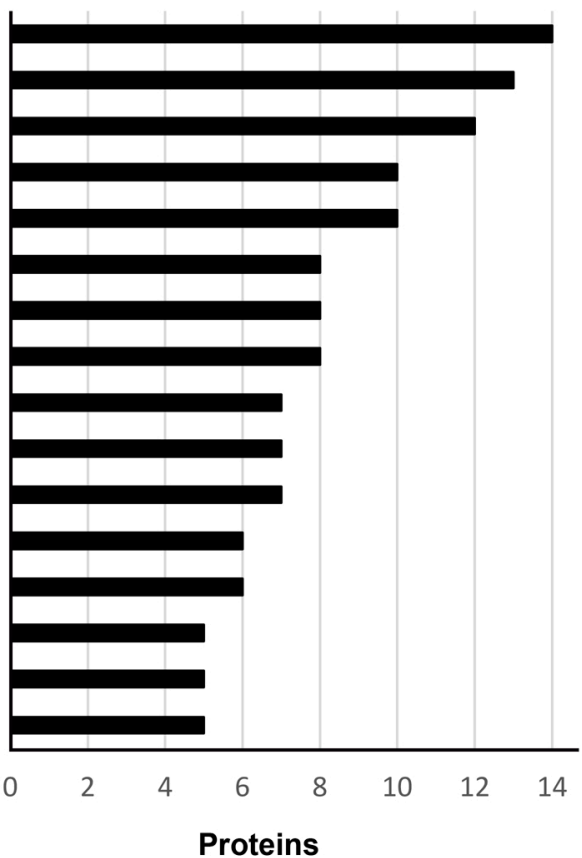

